\title{
A methodology for tracking the "fate" of technological interventions in agriculture
}

\author{
Laura German, ${ }^{1}$ Jeremias Mowo, ${ }^{2}$ and Margaret Kingamkono ${ }^{3}$ \\ ${ }^{1}$ African Highlands Initiative, World Agroforestry Centre (ICRAF), 26416 Kampala, Uganda; ${ }^{2}$ Mlingano Soil Research Institute, \\ Tanga, Tanzania; ${ }^{3}$ Selian Agricultural Research Institute, Arusha, Tanzania
}

Accepted in revised form May 31, 2005

\begin{abstract}
The primary focus of agricultural research and extension in eastern Africa is technology generation and dissemination. Despite prior critiques of the shortcomings of this approach, the consequences of such activities continue to be measured through the number of technologies developed and introduced into the supply chain. At best, impact is assessed by the total numbers of adopters and by the household and system factors influencing adoption. While the diffusion research tradition has made substantive advances in recent decades, attention to what happens to technologies after adaptive, on-farm research trials continues to be limited in practice. While a host of newer approaches designed to correct for past shortcomings in diffusion research is now available, integrative methodologies that capitalize on the strengths of these different traditions are sorely needed. This article presents a more encompassing methodology for tracking the fate of technological interventions, illustrating the potential applications of findings for enhancing the positive impact of agricultural research and extension in the region.
\end{abstract}

Key words: Agricultural research and extension, Diffusion of innovations, Eastern Africa, Farming systems, Technology adoption

Laura German holds a BSc in Agricultural Engineering from Cornell University (2001) and a PhD in Ecological Anthropology from the University of Georgia (2001). Following many years of involvement in Latin America, she took a position in 2002 as Scientist for the World Agroforestry Centre (ICRAF) under the African Highlands Initiative, an ecoregional program of the Consultative Group for International Agricultural Research (CGIAR) and a network of the Association for Strengthening Agricultural Research in East and Central Africa. Her current research interests include theoretical and applied work in three main areas: (1) research-development linkages; (2) integrated natural resource management at the landscape/micro-catchment scale; and (3) collective action in natural resource management.

Jeremias Mowo holds a BSc in Agriculture (1979) from Dar Es Salaam University and an MSc (1983) and PhD (2000) in Soil Science from Wageningen University. He worked as soil fertility specialist in cotton-based agro-ecosystems for 11 years and coordinated soil research in Tanzania for four years. From 1998 to 2005, he worked under the African Highlands Initiative as Coordinator for the Lushoto Benchmark Site in Tanzania. In May 2005, he took up a two-year contract with the Institut des Sciences Agronomiques du Rwanda (ISAR) as Senior Scientist in Soil and Water Management Research where he is currently spearheading the Integrated Watershed Management approach. His research interests include integrated natural resource management, farmer participatory research, methods and approaches for technology transfer, soil and water management research, organic farming and use of indigenous knowledge in soil management.

Margaret Kingamkono holds a BSc in Agriculture (1994) and an MSc in Agriculture (1996) from the Sokoine University of Agriculture. Since 1995, she has worked for the Ministry of Agriculture and Food Security in Tanzania with a focus on livestock production. She has carried out extensive collaborative work on areas of land resource management, participatory approaches, and crop-livestock-agroforestry interactions. Her research interests include gender and development and integrated natural resource management. 


\section{Introduction}

The primary focus of agricultural research and extension in eastern Africa is on technology generation and dissemination. Despite prior critiques of the shortcomings of the agricultural research and extension complex (Shiva, 1991; Hightower, 1972; Havens and Finn, 1974; de Grassi and Rosset, 2003), the consequences of related activities have been given limited attention. Farming systems approaches have enabled improved "fits" of technologies into complex farming systems (Eklund, 1983; Hagmann, 1999) and adoption studies have provided theoretical and methodological frameworks for understanding patterns and impacts of technology innovation (Rogers, 2003). Nevertheless, throughout much of the world attention to what happens to technologies after adaptive on-farm research trials is limited to numbers and the characteristics of adopters (Wozniak, 1987; Nkonya et al., 1997). Impact is measured through the number of technologies developed and introduced into the supply chain or, at best, through an assessment of total numbers of adopters and the factors influencing adoption. This reflects the pro-innovation bias of change agents who often commission these studies (Rogers, 2003) and the strong influence of an earlier era of adoption research (Ryan and Gross, 1943).

Experience demonstrates that a host of factors influence the success and rates of technology adoption. These include farmer or household characteristics (wealth, age, gender, labor availability), farming system characteristics (land and livestock holdings, slope, access to irrigation), resource access (social networks, planting material, information), properties of the technology itself (how quickly it generates returns, required capital and labor investments), and farmer access to social networks (Shaxson and Bentley, 1991; Negi, 1994; Bunch, 1999; Adamo, 2001; Perz, 2003). If technological innovation is seen as a discrete step (introducing new technologies) rather than a process (from problem definition to technology targeting, testing, monitoring, troubleshooting, and dissemination or discontinuation), many of these patterns and lessons will be lost. Substantial risks may also be introduced into the system through socio-economic gap-widening, or decreased agroecosystem resilience. Furthermore, the opportunity for a more adaptive approach to managing technology innovations and impacts will be lost (see Douthwaite, 2002).

Technology "tracking" is important for several reasons. First, there is increasing recognition that blanket recommendations that fail to take into account household and farming system characteristics do not work (Chambers et al., 1987; Scoones and Thompson, 1994), demonstrating the importance of understanding the specific social and farming system "niches" where technologies most easily fit. We define niche in this context as the suite of social and farming system variables including gender (and gendered activity domains and livelihood constraints), household labor, resource endowments (land, irrigation, livestock), and the like - that facilitate or inhibit easy integration of an innovation into a farming system. Second, technology tracking enables the identification of major bottlenecks to technology access and adoption by different social groups that may suggest critical leverage points for enabling more widespread social benefits from technological innovation. Third, it enables the identification of technological "reinvention" or adaptations - departures from recommended practice - that enable technologies to fit more easily into local farming systems (Bentley, 1990; Reij and Waters-Bayer, 2001). Fourth, such studies can increase the efficiency of research and development (R\&D) interventions by identifying critical leverage points for livelihood and farming system improvements and social networks that either enhance or hinder widespread access to benefits in the absence of external mediation (Adamo, 2001). Finally, positive and negative impacts of technological innovation on livelihood and the environment and the type of farmers benefiting from interventions can be tracked (see Haugerud and Collinson, 1990; Shiva, 1991; de Grassi and Rosset, 2003), adding a much-needed ethical dimension to technological interventions (Cooley, 1995).

Following a brief background in which existing approaches for tracking the fate of agricultural technologies and the need for an integrated approach are illustrated, a methodology is outlined for tracking the fate of technological interventions. The methodology emphasizes technology "spillover" - the spontaneous, farmerto-farmer spread of technologies in the absence of outside mediation - that gives greater insights into adoption and impact than research or extension-mediated diffusion. The paper concludes by illustrating some of the findings of such an approach and implications for improving the targeting and impact of agricultural research and extension programs.

\section{Background}

\section{A history of diffusion research}

Early approaches to researching the diffusion of innovations emerged from the fields of anthropology, geography, sociology, health, marketing, and communications but were consolidated into a single research tradition in the 1960s (Rogers, 2003). While these diverse traditions contributed to a rich body of literature on how the characteristics of adopters, innovations, social networks and systems, and opinion leaders influence the adoption and "re-invention" of innovations, an early study by 
Ryan and Gross (1943), "more than any other study, influenced the methodology, theoretical framework, and interpretations of later students in the rural sociology tradition, and in other research traditions" (Rogers, 2003: 55). This is especially true in developing nations. Here, interest in studying the diffusion of innovations has been strongest in the agricultural sector, which was strongly influenced in the 1960s by a systematic attempt to export the land-grant university and agricultural extension model to developing nations.

The study by Ryan and Gross (1943) used a retrospective survey method to model the diffusion of hybrid corn in Iowa. This study sought to correlate innovativeness (i.e., the time of adoption) with a number of variables such as the adopter's age, education, farm size, income and access to diverse information sources. The methods used by Ryan and Gross and other early diffusion researchers have since been subject to a great deal of critique, and a host of innovations have been introduced into diffusion methodologies themselves (Table 1). Critiques of early approaches include their pro-adoption bias, which leads to an over-emphasis on externally introduced and fixed innovations (i.e., failing to capture re-invention processes taking place after introduction), one-way communication from service providers to end users, and their emphasis on adoption over impact or rejection of introduced innovations. A second critique is methodological. The retrospective "one-off" survey method, in which adoption levels are assessed at a single point in time at the level of individual adopters and technologies, is ill-suited for understanding broader diffusion networks and processes, cause and effect relationships, the interdependencies in the uptake of different innovations, or the role of the broader system (e.g., change agents, institutional and politicaleconomic context) in enabling or hindering adoption (Katz et al., 1963; Mohr, 1969; Rogers, 2003).

While a host of new studies have expanded upon and improved early diffusion research methods (Table 1), these approaches have had little effect on the tracking of agricultural innovations in developing nations. Diffusion studies proliferated in Africa, Asia, and Latin America in the 1960s and early 1970s during a time when NorthSouth technical exchanges were taking off and technological optimism formed the backbone of the development paradigm (Rogers, 2003). As a result, correlational analyses from retrospective surveys in the Ryan and Gross tradition are still the norm (Nkonya et al., 1997; Semgalawe, 1998; Franzel et al., 2002).

The case for an integrated approach for tracking the fate of agricultural innovations

Most of the past critiques leveraged against diffusion studies in diverse disciplines are highly relevant to current practice within the agricultural sector throughout much of the developing world today. Some of the most relevant critiques reflect the need to:

- Move from a focus on adoption to a focus on socioeconomic and environmental impact. The ultimate goal of agricultural R\&D should not be technology adoption but rather positive outcomes on livelihood and sustainability. A growing body of literature highlights negative social and biophysical impacts of technological innovation, including impacts on patterns of resource access and exclusion and impacts of system simplification on agroecosystem resilience (Sharp, 1952; Shiva, 1991; Altieri, 2002; Swanson, 2002; de Grassi and Rosset, 2003). It also highlights approaches for identifying and managing these impacts (Douthwaite et al., 2001, 2002). These approaches reflect a broader trend in development and conservation practice toward adaptive management and social learning approaches (Morgan and Ramirez, 1983; Castellanet and Jordan, 2002; Röling and Wagemakers, 2000), and bring a much-needed ethical dimension into technology generation and dissemination.

- Shift from positivist to constructivist modes of inquiry. The conventional scientific paradigm is guided by a realist-positivist epistemology, which holds that reality exists independent of the human observer, and scientific research is the means to acquire true knowledge about the nature of that reality (Röling, 1996). Agricultural science is deeply rooted within this paradigm. Constructivist inquiry is based upon the premise that the world has multiple, socially constructed realities (Chambers et al., 1992) and recognizes the need to integrate perspectives from diverse actors when trying to gain an understanding of complex systems. By integrating the observations of different actors within a system, constructivist inquiry also minimizes the "individual blame" bias (Rogers, 2003) in determining cause and effect.

- Move away from the source bias (unidirectional transfer of "static" innovations) to understanding the adaptive logic of re-invention. The conventional concept of technologies (i.e., static and research-driven) has obscured the importance of continuous adjustment or "re-invention" of technologies in adapting them to existing farming systems in a way that does not enhance risk or place excessive demands on limited on-farm resources (e.g., capital, land, labor, water, nutrient resources). Methods to capture processes and motives for re-invention must enter standard methodological toolkits for studying diffusion. Some authors point out that a program can only sustain positive impacts if constant technological innovation and adaptive management of smallholder farming systems are encouraged (Bunch, 1999). Faster recognition of this by NGOs than by government or UN-funded 


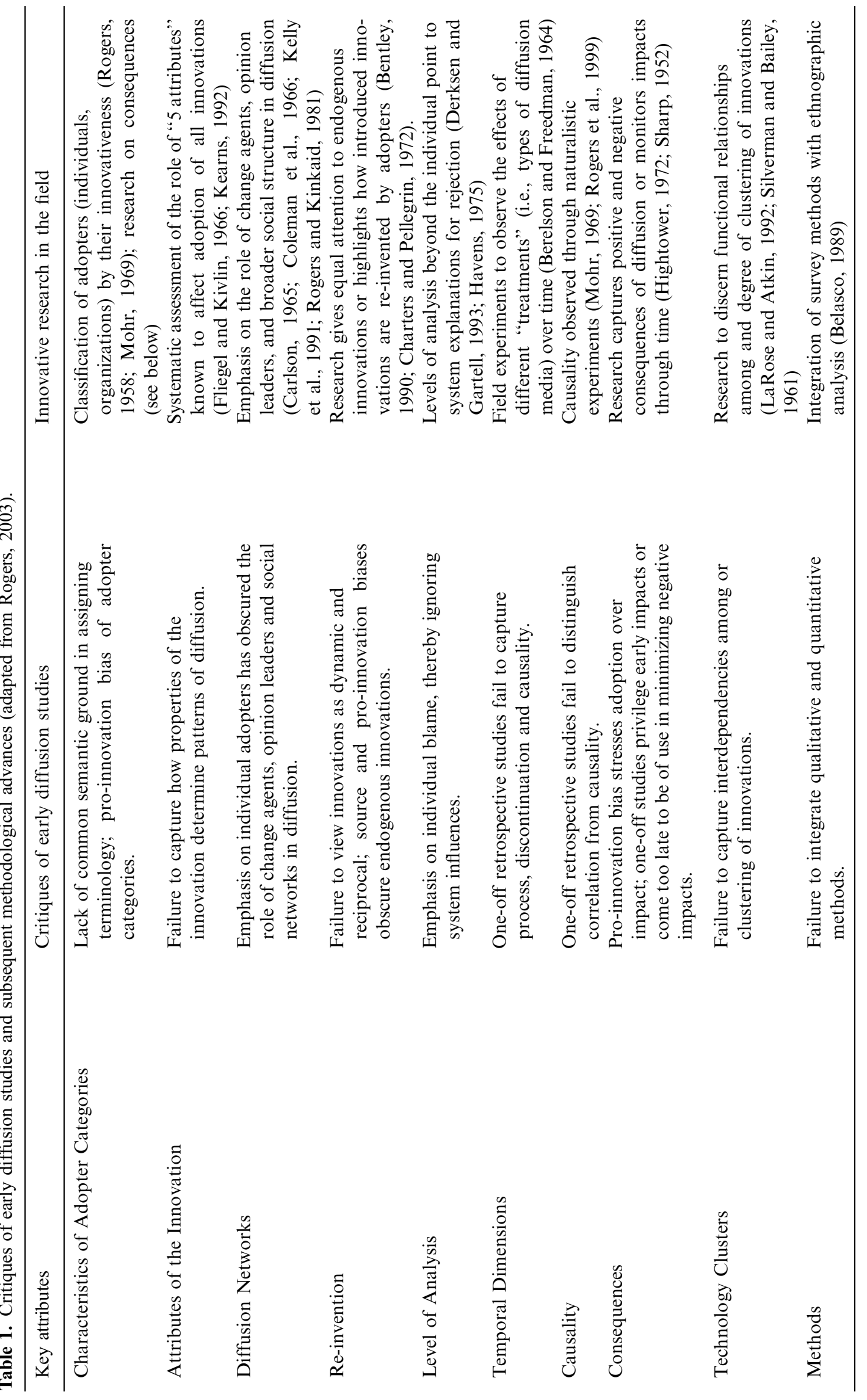


institutions is in large part responsible for their greater success in overcoming adoption barriers to more complex, conservation-oriented technologies (Ibid).

- Embrace a more nuanced understanding of social networks and benefits. An understanding of the role of social networks in the dissemination of innovations is necessary to understand how program benefits can reach more farmers with minimal outside investments (Adamo, 2001), and to understand and minimize the tendency for innovations to widen the socioeconomic gaps within a system through benefits capture by local elites (Havens and Flinn, 1974; Munk Ravnborg and Ashby, 1996; Brosius et al., 1998). Prior research has highlighted the prominent role of interpersonal kinship, friendship, and patronage ties relative to formal avenues of information transfer (Armonia, 1996; Hossain, 1998; Adamo, 2001) as well as the potential for correcting for gap-widening effects through more explicit social targeting of innovations (Röling et al., 1976).

Despite the relevance of these perspectives to agricultural research and development, they remain marginal in practice throughout eastern Africa. If diffusion studies are carried out at all within agricultural research and extension systems, the emphasis continues to be on adoption (obscuring processes of re-invention, rejection and impact), on the individual level of analysis (obscuring system or network effects on adoption), and on quantitative survey techniques (with tenuous assumptions on causality and links to alternative frames of reference). Yet the challenges of bringing the many innovations in diffusion research to bear on professional practice in agriculture are daunting given the host of objectives and methodological approaches characterizing these studies. This article seeks to integrate many of the past advances in diffusion research into a single series of steps for tracking the fate of the most common intervention in agricultural $\mathrm{R} \& \mathrm{D}$ - the introduction of new agricultural technologies.

\section{Program context}

This research was conducted under the rubric of the African Highlands Initiative (AHI), an Ecoregional Program of the Consultative Group for International Agricultural Research (CGIAR) and a network of the Association for Strengthening Agricultural Research in East and Central Africa (ASARECA). The mandate of AHI is to improve farmers' livelihoods in densely settled, highly degraded areas of the eastern African highlands through the development, testing, and institutionalization of new methods and approaches to agricultural research and development. The program's human resources include a small, interdisciplinary regional research team and interdisciplinary site teams composed of staff from National Agricultural
Research and Extension Systems in each country. Benchmark sites in the highlands of Ethiopia, Kenya, Tanzania, and Uganda serve as testing grounds for the formulation and testing of new approaches. This research was carried out in one of these benchmark sites, located in Lushoto District, in the East Usambara Mountains of Tanzania.

New approaches to research and development in AHI benchmark sites are intended for eventual adoption by agricultural research and extension systems throughout the region, whose mandate is predominantly one of agricultural technology development and dissemination. They are formulated through a social and experiential learning approach as site and regional staff come together to plan, field-test, and evaluate approaches in the field. Given this action research orientation to methodology development, both the methodology and the findings presented in this paper constitute "research results" - the methods an outcome of an action research process (where methods testing is done through an iterative process of planning, testing, and modification) and the findings a product of empirical research (application of the methodology).

From 1997 to 2002, AHI tested a participatory process for problem identification and adaptive on-farm research, where new technologies were targeted in response to locally identified problems. Given the large range of problems affecting farmers - cutting across crop, soil, and livestock components - technologies were introduced in clusters. These included crop germplasm (for staple and high-value vegetable crops), soil management practices (soil conservation structures and integrated soil fertility management measures) and livestock innovations (housing, feed, and sanitation). In some cases technology clustering was intentional and planned, as with the combination of soil fertility management practices and crop germplasm or with the integration of soil and water conservation and livestock (manure usage during terrace construction and terrace stabilization with fodder). In cases where clustering was not intentional, this simultaneous introduction of new technologies nevertheless created an opportunity for farmers to creatively combine technologies on their farms. While the methodology described below may be used to track the fate of a single technology once introduced into a system, it is more illustrative of how properties of the technology, farming system, and social networks influence diffusion when compared across different types of technologies.

\section{Methodology}

\section{Objectives}

An integrated methodology for tracking the fate of technological interventions must stem directly from an 
integrated set of objectives. The following objectives were identified.

General Objective: To gain insight into the spontaneous spread and adoption of technologies, thereby enabling the design of strategies to enhance the positive impacts of technology generation and dissemination.

Specific Objectives:

(a) To understand the primary pros, cons, and adoption barriers of each technology;

(b) To understand the characteristics of households and farming systems where different technologies are spontaneously adopted;

(c) To identify forms of and motivations for social and biophysical innovation (i.e., re-invention);

(d) To characterize social networks through which technologies flow in the absence of outside mediation; and

(e) To identify the socio-economic and environmental impacts of introduced technologies.

\section{Research questions}

The following research questions were designed to operationalize the above objectives.

- What are the primary pros, cons, and adoption barriers of each technology?

- What are the social and farming system "uptake niches" of different technologies?

- What farmer innovations (i.e., re-inventions) were made to introduced technologies?

- What is the nature of social networks through which technologies flow spontaneously?

- Did introduced or modified technologies have any impact on livelihood or social dynamics?

- Did introduced or modified technologies have any impact on agroecosystem resilience?

Answers to these questions will enable the design of more informed and responsible interventions in the agricultural sector. Pros, cons, and adoption barriers identified in pilot sites enable technologies to be improved upon to increase their accessibility to a wide range of farmers. They also allow for more strategic design of interventions based on limiting factors (germplasm, technical assistance). Identification of social and biophysical uptake niches is needed for the design of technologies targeted to different types of farmers and farming systems, to minimize the gap-widening effects of technology introductions (Rogers, 2003). Identification of re-invention processes and their underlying motives enables R\&D actors to gain a deeper understanding of how technologies must change to adapt to local farming systems and the inclusion of new messages derived from farmer innovations within planned dissemination strategies. Understanding the social networks through which technologies flow in the absence of outside interventions gives an understanding of the processes of social inclusion and exclusion operating within the social system and points to possible entry points for fostering more equitable benefits from technology dissemination. Finally, illuminating the positive and negative consequences of diffusion is needed so that these can be managed explicitly to enhance the positive impacts of technology dissemination on livelihoods, equity, and agroecosystem resilience.

\section{Methodological steps}

The methodology for addressing each of the proposed research questions was broken down into four basic steps that correspond with the need to integrate constructivist inquiry into formal survey methods for tracking technologies. These include:

Step 1: Constructivist inquiry to identify basic patterns in uptake. While personal experience and familiarity with the literature gives researchers knowledge of important factors influencing the adoption of technologies falling within their area of expertise, farming systems and farmer decision-making processes are extremely complex. This serves as an absolute constraint on what researchers themselves can know a priori about potential variables influencing uptake. It is essential, therefore, that surveys designed to track technologies begin with a broadly participatory assessment of patterns of uptake as observed by farmers themselves. Focus group discussions with diverse groups (e.g., adopting and non-adopting farmers, primary and secondary adopters, or gender and wealth-based groupings) can be used for this purpose. Ideally, focus group discussions with new groups of farmers should be repeated until significant overlap is found in the answers given, and it therefore can be assumed that a comprehensive understanding of patterns of technology uptake and re-invention (as observed by farmers) has been attained.

Step 2: Tracking surveys with on-farm interviews. Variables identified by farmers as influencing adoption (from Step 1) are then compiled along with variables intuited by researchers from the literature or direct observation and integrated into a formal tracking survey that is made more robust through local "ground-truthing" " of the relevant variables to be tracked. This survey is applied in the form of a structured household interview to capture the household and farming system characteristics of a large number of adopters, a standard step in more econometric analyses of diffusion. By conducting these formal surveys on-farm, a further opportunity is provided to capture information that lends itself to more qualitative case study methods (e.g., re-invention, and social and biophysical spin-offs). 
Different sampling procedures can be used for these tracking surveys depending on the ultimate objective. Standard random sampling techniques may be used if the interest is to conduct a rigorous econometric analysis of adoption variables. Alternatively, a form of snowball sampling may be used if the interest is to understand social networks through which technologies diffuse in the absence of outside interventions or how adoption levels and technologies themselves change through successive levels of "spillover" (Figure 1). The "level of spillover" is defined as the distance (measured in terms of the number of social transactions) the technology has spread from the original farmer involved in adaptive on-farm research. Technology adoption among farmers directly involved with project personnel may have a bias due to motives for adoption that are de-linked from the actual benefits derived from the technology itself (Mowo, pers. observation). ${ }^{2}$ It is therefore important to designate such farmers as " $\mathrm{L}_{0}$ " (level zero), indicating that spontaneous sharing of technologies among farmers has not yet occurred. Successive levels of spillover are therefore defined in relation to how many transactions the technology has passed through to be adopted. Farmers adopting from "project farmers" would therefore be designated " $\mathrm{L}_{1}$ " or level one of spillover, and so on (Figure 1).

Following these spillover pathways, a certain percentage of farmers at each level are interviewed to document household and farming system characteristics, the nature of social networks through which the technology was acquired, and with whom they in turn shared the technology (enabling identification of farmers at the next level of spillover). These structured surveys are combined with more open-ended interviews and farm visits when more detailed information on processes (e.g., farmer re-invention, social and environmental impact, technology adoption) is required. It is important that tracking surveys target not only adopting farmers, but also randomly selected non-adopters, thereby allowing for emerging patterns of adopters to be compared with the demographics of the community at large (i.e., a "control group").
Step 3: Data analysis. The third step involves statistical analysis of data from tracking surveys and qualitative analysis of data from semi-structured interviews and farm visits. Basic patterns observed for each objective and associated research question are discerned at this time. The total number of adopters can only be assessed by extrapolating out from the percentage of farmers interviewed at each level, ${ }^{3}$ yet care must be taken in interpreting these numbers if farmers have not kept records on technology sharing due to known inaccuracies in recall data (Rogers, 2003). The data are nevertheless useful in understanding relative numbers such as the percentage of exchanges characterized by kinship ties or the percentage of female adopters.

Step 4: Focus group discussions to interpret emerging findings. Data analysis and interpretation by researchers themselves (Step 3), is generally the final step of econometric analysis. However, a number of assumptions must be made about the reasons for observed patterns in the absence of additional "ground truthing" to explicitly integrate the interpretations of farmers or other actors in the system. Pattern interpretation by different actors can be useful for several reasons. First, patterns that would otherwise be difficult to observe are fed back to farmers or others, giving them a chance to contribute further in interpreting their own behavioral patterns. It also gives a more complete and nuanced view of farmer behavior by integrating local logic with scientific logic in interpreting observed patterns.

Different research questions are best answered through different forms of data. The sequencing of qualitative, constructivist steps with more quantitative surveys therefore provides an opportunity to match research questions with the most appropriate methodological steps (Table 2). While integration of recent advances in diffusion research into a single methodology has the obvious disadvantage of minimizing the detail of lessons that might be learned from more targeted methodologies, the advantages are also clear. In addition to providing a manageable methodology for research and extension systems to track (and to take responsibility for) the

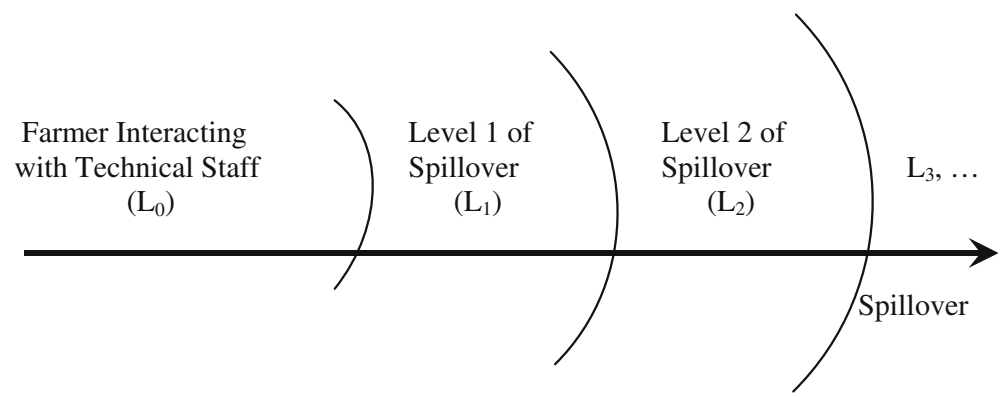

Figure 1. Levels of technology "spillover" relative to project interventions. 
"fate" of their interventions, the methodology offers clear improvements over the model currently in use in eastern Africa across a host of evaluation criteria (Table 3).

\section{Results and applications}

As the objective of this paper is to present a methodology as much as it is to present empirical research results, the latter are chosen selectively to illustrate different aspects of the method itself.

Case No. 1: "Ground truthing” surveys in farmers' observations

Focus group discussions carried out with AHI and non-AHI farmers pointed to several important variables influencing the adoption of technologies introduced by the project. The following variables were identified as influencing adoption of soil conservation technologies and integrated as new variables in the tracking survey (i.e., indicated in bold font in Tables 4 and 5): (a) limited access to technical assistance due to limited number of village para-professionals; (b) limited access to organic nutrient resources for the implementation of bench terraces, required to off-set the decline in soil fertility resulting from topsoil disturbance; (c) labor requirements, including total numbers of household members and their age; and (d) presence of permanent crops, hindering the ability to implement physical structures.

In addition to these variables, scientists identified through their own observations a number of additional variables likely to influence the adoption of soil and water conservation technologies in particular (i.e., indicated in grey font in Table 5). These included: (a) soil quality prior to implementing soil conservation measures, presumably influencing a farmer's motivation for conserving his or her fields; (b) access to irrigation water, assuming that farmers are more likely to invest in activities with longer-term returns (i.e., natural capital) in areas where cash crops are cultivated; and (c) landscape position, including the proximity of conserved plots to households (which influences the ability to transport manure to terraces and keep watch over cash crops) and water resources.

Impacts stemming from the adoption of soil conservation practices were also identified through focus group discussions with adopting farmers and from researchers and integrated into the tracking survey. Those impacts identified by farmers included increased crop vigor, soil fertility, and soil water holding capacity (i.e., indicated in bold font in Table 5). Researchers then wanted to monitor the influence of these locally identified variables on related factors, including income (presumably enhanced through increased crop vigor and soil fertility) and the incidence of weeds (presumably increased through soil fertility improvements) (indicated in grey font in Table 5). They also wished to know the total area under which the new technologies had been applied, as an additional indicator for measuring impact.

A generic survey form integrating standard farming system and household variables likely to be important, irrespective of the particular technology being tracked or other contextual factors related to the region where work is being carried out, is shown in Table 4. Additional variables particular to soil conservation technologies and corresponding to farmer-identified adoption barriers

Table 2. Methods utilized to address each research question.

\begin{tabular}{ll}
\hline Research question & Methods \\
\hline $\begin{array}{l}\text { Pros and Cons of the Technology } \\
\text { Major Adoption Barriers }\end{array}$ & Focus group discussions (pre) \\
Social and Farming System Niches & Focus group discussions (pre and post) \\
& Tracking survey \\
& Focus group discussions (pre and post) \\
Farmer Innovations & Tracking survey \\
& Semi-structured interview \\
Social Networks & Farm visits \\
Livelihood Impacts & Focus group discussions (pre) \\
& Semi-structured interviews \\
Agroecosystem Impacts & Farm visits \\
& Tracking survey \\
& Focus group discussions (post) \\
& Focus group discussions (pre and post) \\
& Semi-structured interviews \\
& Tracking survey \\
\end{tabular}


TEChNOLOGICAL INTERVENTIONS IN AGRICULTURE

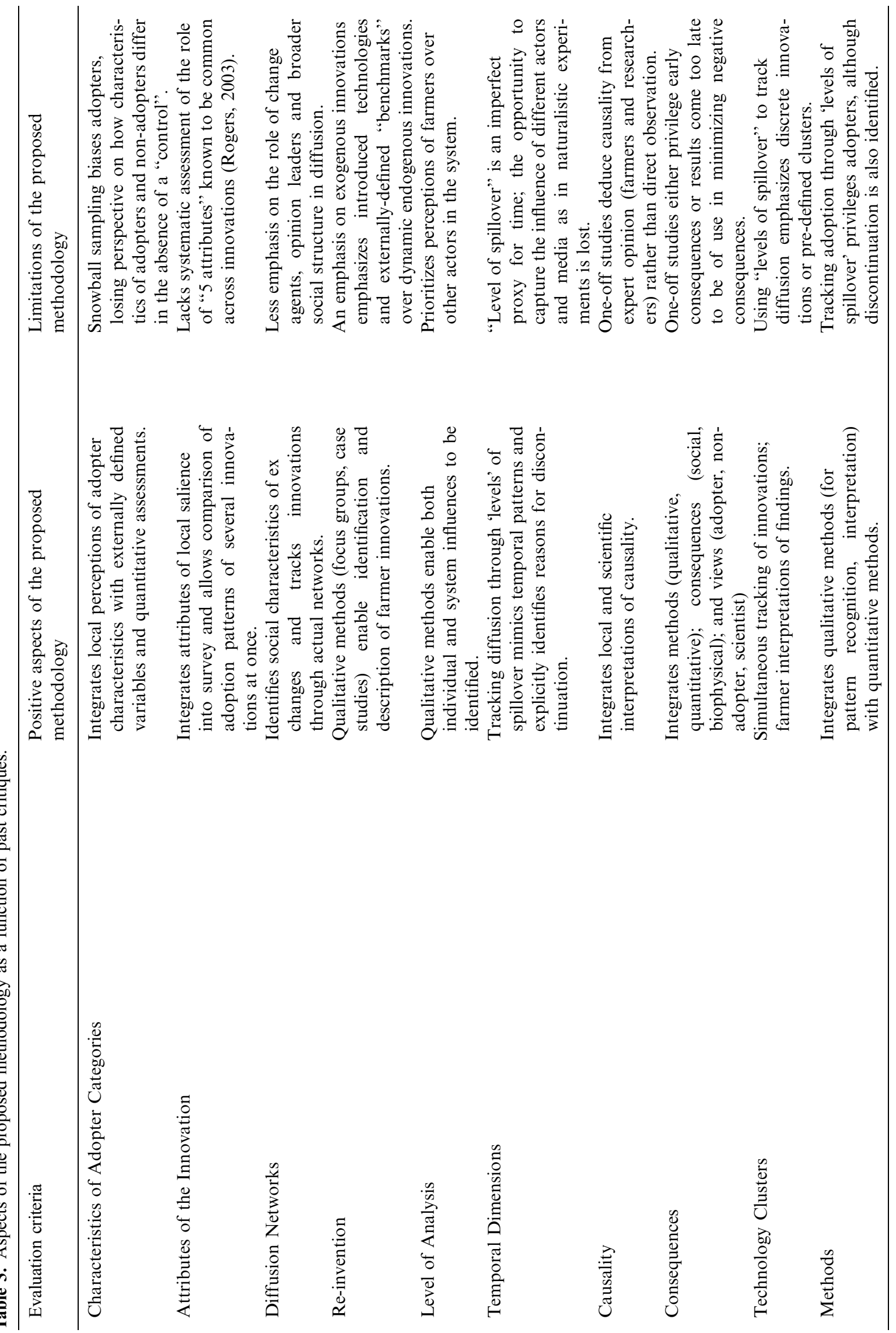


Laura German et al.

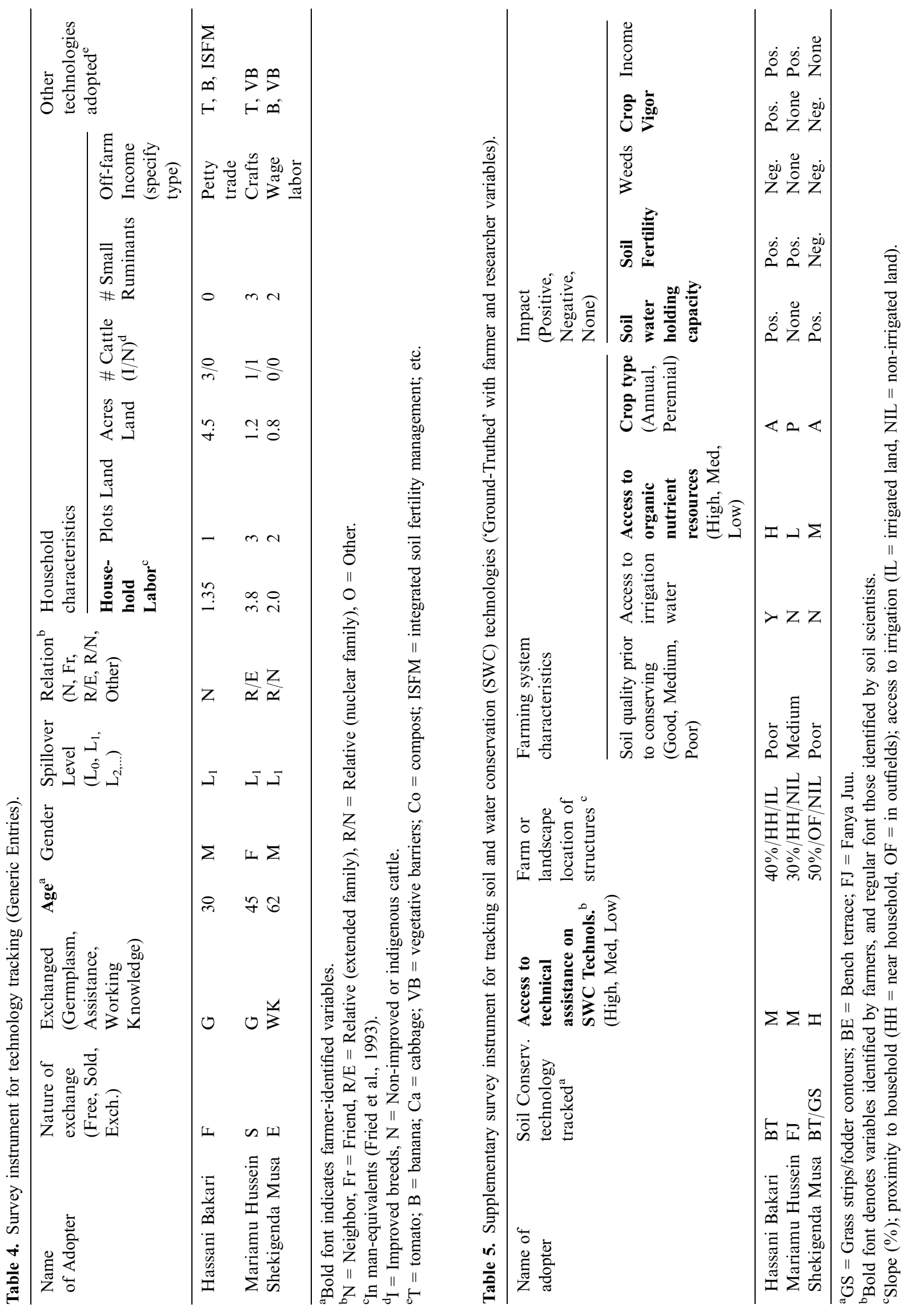


(Table 6) were added to the generic survey, thereby "ground-truthing" the tracking survey in the properties of the specific technology being tracked and in farmer-identified variables. These additional variables are shown in Table 5. By systematically tracking variables of interest to farmers as well as researchers, all actors in the system (i.e., research, extension, farmers) can gain a more systematic awareness of the impacts of interventions as viewed by other actors in the system.

\section{Case No. 2: Tracking adoption bottlenecks}

A second case illustrates the importance of understanding patterns of adoption throughout successive levels of spillover. Of diverse technologies introduced to Lushoto by AHI, one of the most popular among diverse types of farming households was a high-yielding variety of banana coupled with improved agronomic practices for planting and managing the crop. Despite its popularity, the observed spillover from $\mathrm{L}_{1}$ to $\mathrm{L}_{2}$ farmers was just $11 \%$ of the spillover from $\mathrm{L}_{0}$ to $\mathrm{L}_{1} 3$ years after introduction (265 adopters at $\mathrm{L}_{1}$, compared to 30 at $\mathrm{L}_{2}$ ). This contrasts with $34 \%$ for tomato seed and $13 \%$ for soil and water conservation technologies, the latter being notorious worldwide for slow adoption despite its relative success in the pilot site. Additionally, despite the broad social and farming system niches and the appeal of the banana technology, the maximum level of spillover was two exchanges $\left(\mathrm{L}_{2}\right)$. Furthermore, unlike tomato, most banana and soil and water conservation technologies (both materials and technical assistance) were exchanged among farmers free of charge.

In tracking these technologies through successive levels of spillover and discussing patterns with farmers in focus group discussions, it was determined that the only reason for slow adoption was the limited availability of germplasm. This occurred because outside intervention in the technology's diffusion stopped after the adaptive research phase and the propagation rate of suckers (for farmer to farmer "spillover") is slower than for other crops. In tracking the social relationships characterizing technology sharing, it was found that banana had the highest proportion of exchanges characterized by family ties, further suggesting that it is a scarce commodity for which sharing is done discriminately. The implications of these findings for reaching more farmers are clear. Since social and environmental impacts are positive yet benefits inequitably distributed, methods for multiplying and ensuring more equitable access to banana suckers are needed. Yet foresight in the eventual consequences of rapid dissemination (i.e., the potential for increased pests and disease) is also needed so that an awareness of the need for in situ preservation of local germplasm may be fostered. This genetic diversity is a source of resilience in socio-ecological systems. In encouraging retention of alternative germplasm that may be better adapted to a wide range of future environmental stresses or providing a rather secure fall-back (given its adaptation to local environmental conditions), this enhances the capacity of local communities to respond to unpredictable future conditions.

\section{Case No. 3: Tracking social innovations}

Semi-structured interviews were utilized to identify technological innovations, including changes in the technology itself, changes in the farming system to accommodate the technology, and social innovations that enhanced technology adoption. The last of these is the subject of this case due to the limited treatment of such innovations in the literature.

During the tracking survey and on-farm interviews, a number of social innovations were identified that enabled technology adoption and improved livelihood. For the

Table 6. Adoption barriers identified through focus group discussions.

\begin{tabular}{lc}
\hline Technology & Adoption barriers identified by farmers \\
\hline Banana Germplasm & Low availability of planting material (suckers); susceptibility \\
to drought. & High cost of seed. \\
Cabbage Germplasm & Limited knowledge of how to make compost; limited alternative \\
Organic nutrient resources & uses of Mucuna; lack of compost materials; limited awareness. \\
Soil and Water Conservation & Presence of annual crops; labor requirements and old age; organic \\
& nutrient resource requirements; limited access to technical \\
& assistance*. \\
Labor requirements; input requirements; limited access to & irrigation \& quality land; dislike of industrial pesticides; limited \\
& access to technical assistance (for agronomic practices).
\end{tabular}

*Tables 4 and 5 illustrate how locally identified variables such as these identified for soil and water conservation technologies are integrated into formal tracking surveys. 
Table 7. Social networks characterizing spontaneous spread of technologies.

\begin{tabular}{llllll}
\hline Relationship & $\begin{array}{l}\text { Banana } \\
(\% \text { exchanges })\end{array}$ & $\begin{array}{l}\text { Soil fertility } \\
\text { management } \\
(\% \text { exchanges })\end{array}$ & $\begin{array}{l}\text { Soil and water } \\
\text { conservation } \\
(\% \text { exchanges })\end{array}$ & $\begin{array}{l}\text { Tomato } \\
(\% \text { exchanges })\end{array}$ & $\begin{array}{l}\text { Ave. } \\
(\%)\end{array}$ \\
\hline Kin & $\mathbf{5 3}$ & $\mathbf{4 3}$ & $\mathbf{4 0}$ & $\mathbf{5 7}$ & $\mathbf{4 8}$ \\
(Nuclear Family) & $(26.5)$ & - & $(25)$ & $(14)$ & $(22)$ \\
(Extended Family) & $(26.5)$ & - & $(15)$ & $(43)$ & $(28)$ \\
Non-Kin & $\mathbf{4 7}$ & $\mathbf{5 7}$ & $\mathbf{6 0}$ & $\mathbf{4 3}$ & $(21.5)$ \\
(Friend) & $(41)$ & $(28.5)$ & $(24.5)$ & $(21.5)$ & $(20.1)$ \\
(Neighbor) & $(6)$ & $(28.5)$ & $\mathbf{5 2}$ & $\mathbf{1 0 0}$ & $\mathbf{9 5}$ \\
Male adopters $\left(\mathrm{L}_{1}\right)$ & $\mathbf{9 8}$ & $\mathbf{8 6}$ & $\mathbf{1 8}$ & $\mathbf{0}$ & $\mathbf{5}$ \\
Female adopters $\left(\mathrm{L}_{1}\right)$ & $\mathbf{2}$ & $\mathbf{1 4}$ & & & $\mathbf{1 0 0}$ \\
\hline
\end{tabular}

implementation of bench terraces, one of the most common complaints was the high demand placed on household labor and organic nutrient resources (Table 6). Farmers in Kwalei village, Lushoto, were found to have adapted the traditional labor-sharing practice of Ngemo to assist one another in the construction of bench terraces. Another important social innovation identified during household interviews emerged from the introduction of a variety of tomato with high market value, coupled with optimal use of manure and urea. Youth with little access to land had made an agreement with an elder landowner with ample access to valley bottoms (ideal for tomato) but limited labor and organic nutrient resources. While the cost of inputs and all proceeds were shared equally, the labor-intensive work (including transporting farmyard manure and the preparation of stakes to support the tomato plants) was done by the youth. Such synergies were beneficial to all involved, complementing their respective resource endowments (labor versus land). This also highlighted a potentially negative environmental side-effect of this social innovation, namely the transfer of a limited resource (organic nutrient resources) from some households and landscape niches to others. While this may simply be a way of making more economically and mutually beneficial use of existing resources, it also introduces risk into the system by restricting the use options of niches from which these resources are diverted.

Other innovations included synergies between technologies and resource investments. For example high-value crops were combined with investments in bench terrace construction so that organic nutrient resources could be utilized to ensure economic returns while also enhancing soil fertility long-term. A social innovation associated with this practice included the joint hiring of a lorry to bring manure to the village for use in tomato production and bench terrace fertilization, offsetting the high organic nutrient resource demands of new technologies. Such innovations need to be captured by research and extension, in order to incorporate some of the principles (e.g., social synergies, off-setting negative spin-offs from new organic nutrient resource flows) into dissemination strategies.

\section{Case No. 4: Tracking social networks through which technologies flow spontaneously}

Tracing technologies through different levels of spillover enables the identification of the social networks through which technologies flow in the absence of external mediation. Table 7 summarizes social relationships characterizing technology spillover. On average, no difference was found in the tendency to share with kin and non-kin. When findings were disaggregated by technology, however, there was a stronger bias toward kin for the more economically important crops (i.e., banana, tomato) compared to the more complex natural resource management technologies, whose benefits were only seen as medium-term. More strikingly, while an initial attempt was made by project personnel to enhance gender equity by working equally with men and women in adaptive research, $95 \%$ of the spillover or $L_{1}$ exchanges were oriented toward male farmers. For cash crops, exchanges with women were negligible. These sharp differences stem not only from culturally prescribed domains of activity but from information exchanges characterized by patrilocal societies. These data illustrate the need to understand how the social context conditions patterns of inclusion and exclusion of benefits emanating from introduced innovations, and the need to field-test new approaches for minimizing "elite capture" by certain social groups.

Data on types of exchanges (Table 8) further reveal that most exchanges occur at no cost to the adopting farmers. This represents a positive trend with regard to maximizing access by resource-poor farmers. However, while knowledge-intensive technologies (soil fertility management, soil and water conservation) are never characterized by cash exchanges, $12 \%$ of the exchanges of economically important crops are. The tendency to 
Table 8. Types of exchanges for different technologies.

\begin{tabular}{llcccc}
\hline $\begin{array}{l}\text { Type of } \\
\text { exchange }\end{array}$ & $\begin{array}{l}\text { Banana } \\
(\% \text { exchanges })\end{array}$ & $\begin{array}{l}\text { Soil fertility } \\
\text { management } \\
(\% \text { exchanges })\end{array}$ & $\begin{array}{l}\text { Soil and water } \\
\text { conservation } \\
(\% \text { exchanges })\end{array}$ & $\begin{array}{l}\text { Tomato } \\
(\% \text { exchanges })\end{array}$ \\
\hline Free & 88 & 67 & 75 & 57 & 71.8 \\
Sold & 12 & 0 & 0 & 43 & 13.8 \\
Exchanged & 0 & 33 & 25 & 0 & 14.5 \\
\hline
\end{tabular}

place a higher value on technologies that bring in more income, and to minimize the value of those that are more knowledge-intensive or for which returns are longer-term, suggests that financial barriers to technologies with high income-generating potential may exist for some families. The effect of differential access to income-generating technologies is also a concern due to the tendency for differential adoption to widen the socio-economic gap (Rogers, 2003). It is important also to ensure that prices charged for technologies with broader socio-economic uptake niches (for example, banana) do not hinder access among families with very limited income.

If some groups are found to be excluded due to the cost of technologies or to limited access to social networks through which technology flows, alternative means of propagating germplasm to ensure access can be put into place. Rules and monitoring for equitable benefits sharing may also need to be established to minimize the tendency for "elite capture" of outside resources (e.g., program benefits, technologies) among dominant groups.

\section{Case No. 5: Tracking agroecosystem impacts}

To research the impact of introduced technologies on the farming system so as to maximize positive and minimize negative spin-offs, the potential and perceived farming system impacts identified by farmers and researchers were integrated into the tracking survey. Questions focusing on the reallocation of on-farm resources were also included in more qualitative case studies and semi-structured interviews.

Farmer testimonies indicated that the spin-offs from technology introduction were significant for other components of the farming system. For most technological interventions, these included diversions of land, labor, and nutrients from other system components (generally from staple to cash crops and hillsides to valley bottoms); positive or negative impacts on soil characteristics (water-holding capacity, fertility, erosion); positive or negative changes in the incidence of pests, disease and weeds; and changes in levels of purchased inputs (Table 9). Adoption of tomato technologies, for example, increased the incidence of pests and diseases (from decreased crop rotation), increased the incidence of weeds (a spin-off of higher soil fertility), and increased the use of pesticides. Increased nutrient demands of many highyielding crop varieties also require nutrient diversions from other components of the farming system. In Lushoto, this resulted in increased nutrient flows to cash crops and valley bottoms at the expense of staple crops and hillsides. One farmer noted that the substitution of the traditional tomato-bean rotations with two to three consecutive crops of tomato had a negative effect on soil fertility, placed greater demands on limited supplies of farmyard manure, and decreased the yields of subsequent crops. Another farmer stressed positive spin-offs for other system components, including the ability to restore fertility to hillside plots through fallowing as labor was diverted wholesale to tomato cultivation in the valley bottoms.

These data point to the critical importance of monitoring risks to livelihood and agroecosystem resilience stemming from technology dissemination. While agroecological spin-offs may be gradual, the occurrence of some problems such as the incidence of pests and disease increases along with the popularity of the technology. Such "scale effects" should be well understood and intentionally managed by the agricultural R\&D establishment. While contributing to substantial improvements in the income of adopting households (as evidenced by investments in housing, school fees, bicycles, and new enterprises as well as improved food security), overall effects on the quality of life at village level are more mixed.

Positive effects included adoption of some technologies across a wide range of households irrespective of wealth, good management of additional income by some farmers to the benefit of the entire family, and agroecosystem impacts likely to enhance sustainability longterm. However, parallel scenarios of widening socioeconomic gaps, poor investments and negative agroecosystem impacts are also common. This raises a significant challenge for $\mathrm{R} \& \mathrm{D}$ professionals to use a much wider lens and a more robust toolkit when selecting interventions and measuring impact.

\section{Discussion and conclusions}

This paper illustrates the need for a more rigorous approach to technology tracking in eastern Africa, one in 


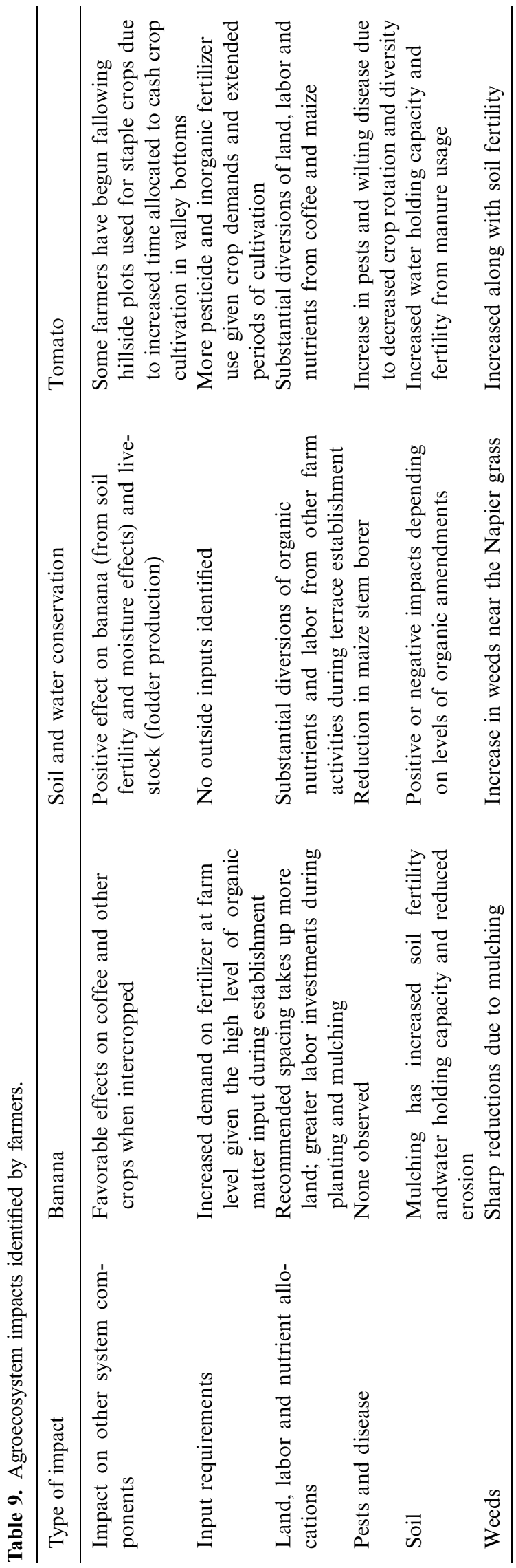

which the merits of different diffusion research traditions are integrated into a single approach. The simple, four-step methodology is presented as a means to expand the conventional approach by integrating the observations of different social actors from the outset (for pattern identification and interpretation), inserting locally identified variables into conventional econometric analyses and expanding the range of observed processes. The approach integrates the current emphasis on major adoption barriers with research on diverse types of adoption impacts (both positive and negative), social networks through which technology flows in the absence of outsider intervention, and farmer innovations that enable technologies to more easily fit into smallholder farming systems.

So what are the implications of such findings for agricultural research and development efforts? Far from being an academic exercise, findings illustrate the critical importance of knowing the fate of introduced technologies. On the one hand, ground-truthing adoption surveys (both the instrument and the interpretation of findings) provide a means for integrating the aspects of greatest salience to farmers into the methodology, thereby enhancing researcher awareness of the variables of greatest importance locally. It also ensures that findings are interpreted with respect to the local context by integrating variables of local concern into spillover studies, monitoring related spin-offs, and involving farmers in the interpretation of findings. While soil conservation technologies are a poor indication of this, Tables 4 and 5 nevertheless illustrate how farmers contribute to the identification of key causal variables influencing technology adoption and impact indicators of high local importance. Identification of adoption barriers through focus group discussions and surveys (in which the breadth of the adoption niche and speed of spillover are each tracked) also enables more strategic design of interventions that enhance desired (and minimize undesired) impacts.

Second, identification of the slow rate of propagation of banana suckers as a key adoption constraint, for example, led to the targeting of collective multiplication plots through the involvement of schools and community-based organizations. Identification of the gender imbalances in technology spillover despite an original emphasis on gender equity (equitable membership in farmer research groups), on the other hand, suggests that attention to gender equity from the outset does not ensure equitable access to technologies during spontaneous spillover processes. New approaches to gender inclusiveness must be tried.

Third, the identification of farmer innovations enables the dissemination of more relevant practices and avails a wider suite of management options to farmers, while the identification of social innovations provides 
insight into the most appropriate organizational strategies for disseminating these innovations. The synergies established between youth and elders with complementary resources, collective action to import organic nutrient resources into the system and build upon traditional labor sharing practices, are examples of social innovations that should be highlighted along with other aspects of technology dissemination.

A final justification and perhaps most important is the realization that solving one problem may create another, as illustrated in the diversion of farm resources from staple crops and the skewed benefit distributions among men and women. While some earlier methods have also emphasized positive and negative consequences of adoption, this methodology is unique in its robust integration of views (farmers and researchers, adopters, and non-adopters), consequences (social and biophysical), and qualitative and quantitative methods (the latter providing, rather unexpectedly, the key insight on gender inequality). Application of such methods as part of standard research practice and the integration of findings into more informed and ethical dissemination processes is sorely needed in the eastern African region to enhance accountability of the agricultural R\&D establishment. This will only happen if improved awareness is coupled with institutional learning processes on successful ways to enhance positive and minimize negative social and environmental impacts of technological innovation. This is where the ethics of science and development comes in - by ensuring that interventions are not only sought by the end users but are accompanied by mechanisms to account for and manage the full range of impacts they may create - and where greater attention needs to be placed in the future.

\section{Notes}

1. We use the term "ground-truthing" to refer to a process through which knowledge or a process of inquiry (including the variables used to track change) is adapted to site-specific conditions, as observed either by farmers or by researchers interacting closely with local communities or the phenomena under observation.

2. For example, social status derived from interacting with outsiders or a desire to extract other benefits from project personnel.

3. If only $20 \%$ of $L_{1}$ farmers are interviewed, for example, and it is found that they, in turn, shared technologies with 100 farmers, then the number of $\mathrm{L}_{2}$ farmers will not be 100 but 500 .

\section{References}

Adamo, A. (2001). Participatory Agricultural Research Processes in Eastern and Central Ethiopia: Using Farmers' Social Networks as Entry Points. Cali, Colombia: CIAT Occasional Publications Series No. 33. CIAT.

Altieri, M. A. (2002). "Agroecology: The science of natural resource management for poor farmers in marginal environments." Agriculture, Ecosystems and Environment 1971(2002): 1-24.

Armonia, R. (1996). "Personal networks and agricultural extension in the Philippines." In P. Blunt and D. M. Warren (eds.), Indigenous Organization and Development, (pp. 239-253). London, England: Intermediate Technology Publications.

Belasco, D. B. (1989). Adoption of Community Water Systems: An Area Study in Three Villages in Muhafzat Kofr-Shaykh, Egypt. PhD dissertation. University of Denver, Denver, Colorado.

Bentley, J. (1990). “Conocimiento y experimentos espontáneos de campesinos Hondureños sobre el Maíz Muerto (Knowledge and spontaneous experiments of Honduran peasants on maize ear rot)." Manejo Integrado de Plagas 17: 16-26.

Berelson, B. and R. Freedman (1964). "A study in fertility control." Scientific American 210(5): 29-37.

Brosius, J. P., A. L. Tsing, and C. Zerner (1998). "Representing communities: Histories and politics of community-based natural resource management." Society and Natural Resources 11: 157-168.

Bunch, R. (1999). "Reasons for non-adoption of soil conservation technologies and how to overcome them." Mountain Research and Development 19(3): 213-220.

Carlson, R. O. (1965). Adoption of Educational Innovations. Eugene, Oregon: Centre for the Advanced Study of Educational Administration, University of Oregon.

Castellanet, C. and C. F. Jordan (2002). Participatory Action Research in Natural Resource Management: A Critique of the Method Based on Five Years' Experience in the Transamazonica Region of Brazil. New York, New York: Taylor and Francis.

Chambers, R., R. A. Pacey, and L. Thrupp (1987). Farmer First: Farmer Innovation and Agricultural Research. London, England: Intermediate Technology Publications.

Chambers, D. E., K. R. Wedel, and M. K. Rodwell (1992). "Qualitative research methods and the constructivist paradigm in the evaluation of social programs and policies." In D. E. Chambers (ed.), Evaluating Social Programs, (pp. 288332). Boston, Massachusetts: Allyn and Bacon.

Charters, W. W. and R. S. Pellegrin (1972). "Barriers to the innovation process: Four case studies of differentiated staffing." Educational Quarterly 9: 3-4.

Coleman, J. S., E. Katz, and H. Menzel (1966). Medical Innovation: A Diffusion Study. New York, New York: Bobbs-Merrill.

Cooley, M. (1995). "The myth of the moral neutrality of technology." AI \& Society 9: 10-17.

de Grassi, A. and P. Rosset (2003). A New Green Revolution for Africa? Myths and Realities of Agriculture, Technology and Development. Oakland, Caifornia: Institute for Food and Development Policy. 
Derksen, L. and J. Gartell (1993). "The social context of recycling." American Sociological Review 58: 434-442.

Douthwaite, B. (2002). Enabling Innovation: A Practical Guide to Understanding and Fostering Technological Change. London, England: Zed Books.

Douthwaite, B., N. C. de Hann, V. Manyong, and D. Keatinge (2001). "Blending 'hard' and 'soft' science: The 'follow-thetechnology' approach to catalyzing and evaluating technology change." Conservation Ecology 5(2): 13.

Douthwaite, B., J. D. H. Keatinge, and J. R. Park (2002). "Evolutionary learning selection: A model for planning, implementing and evaluating participatory technology development." Agricultural Systems 72(2): 109-131.

Eklund, P. (1983). "Technology development and adoption rates: Systems approach for agricultural research and extension." Food Policy May: 141-153.

Fliegel, F. C. and J. Kivlin (1966). "Attributes of innovations as factors in diffusion." American Journal of Sociology 72(3): 235-248.

Franzel, S., J. K. Ndufa, O. C. Obonyo, T. E. Bekele, and R. Coe (2002). "Farmer-designed agroforestry trials: Farmers' experiences in Western Kenya." In S. Franzel and S. J. Scherr (eds.), Trees on the Farm: Assessing the Adoption Potential of Agroforestry Practices in Africa, (pp. 111-123). Wallingford, UK: CABI Publishing.

Fried, H. O., C. A. Knox Lovell, and S. S. Schmidt (1993). The Measurement of Productive Efficiency: Techniques and Applications. Oxford, UK: Oxford University Press.

Hagmann, J. (1999). Learning Together for Change: Facilitating Innovation in Natural Resource Management through Learning Process Approaches in Rural Livelihoods in Zimbabwe. Weikersheim, Germany: Margraf Verlag.

Haugerud, A. and M. Collinson (1990). "Plants, genes and people: Improving the relevance of plant breeding in Africa." Experimental Agriculture 26: 341-362.

Havens, A. E. (1975). "Diffusion of new seed varieties and its consequences: A Colombian case." In R. E. Dumett and L. J. Brainard (eds.), Problems of Rural Development: Case Studies and Multidisciplinary Perspective, (pp. 94-111). Leiden, Netherlands: Brill.

Havens, A. E., and W. L. Finn (1974). "Green revolution technology and community development: The limits of action programs." Economic Development and Cultural Change 23: 469-481.

Hightower, J. (1972). Hard Tomatoes, Hard Times: The Failure of America's Land Grant Complex. Cambridge, Massachusetts: Schenkman.

Hossain, S. M. A. (1998). “Agricultural technology and development communication networking patterns in differentially developed villages of Bangledesh." Journal of Sustainable Agriculture 12(1): 57-77.

Katz, E., M. L. Levin, and H. Hamilton (1963). "Traditions of research on the diffusion of innovations." American Sociological Review 28: 237-253.

Kearns, K. P. (1992). "Innovations in local government: A sociocognitive network approach." Knowledge and Policy 5(2): 45-67.

Kelly, J. A., J. S. St. Lawrence, Y. E. Diaz, L. Y. Stevenson, A. C. Hauth, T. L. Brasfield, S. C. Kalichman, J. E. Smith, and M. E Andrew (1991). "HIV risk behavior reduction following intervention with key opinion leaders of population: An experimental analysis." American Journal of Public Health 82(11): 1483-1489.

LaRose, R. and D. Atkin (1992). "Audiotext and the re-invention of the telephone as a mass medium." Journalism Quarterly 69(2): 413-421.

Mohr, L. B. (1969). "Determinants of innovation in organizations." American Political Science Review 63(1): 111-126.

Morgan, G. and R. Ramirez (1983). "Action learning: A holographic metaphor for guiding social change." Human Relations 37(1): 1-18.

Munk Ravnbord, H. and J. A. Ashby (1996). “Organising for local-level watershed management: lessons from Rio Cabuyal Watershed, Colombia." AgREN Network Paper 65: 1-14.

Negi, G. C. S. (1994). "High yielding vs. traditional crop varieties: A socio-agronomic study in a Himalayan village in India." Mountain Research and Development 14(3): 251-254.

Nkonya, E., T. Schroeder, and D. Norman (1997). "Factors affecting adoption of improved maize seed and fertilizer in Northern Tanzania." Journal of Agricultural Economics 48: $1-12$.

Perz, S. (2003). "Social determinants and land use correlates of agricultural technology adoption in a forest frontier: A case study in the Brazilian Amazon." Human Ecology 31(1): 133163.

Reij, C. and A. Waters-Bayer (2001). Farmer Innovation in Africa: A Source of Inspiration for Agricultural Development. London, England: Earthscan.

Rogers, E. M. (1958). "Categorizing the adopters of agricultural practices." Rural Sociology 23(4): 346-354.

Rogers, E. M. (2003). Diffusion of Innovations. 5th edition, New York, New York: Free Press.

Rogers, E. and D. L. Kinkaid (1981). Communication Networks: Toward a New Paradigm for Research. New York, New York: Free Press.

Rogers, E. M., P. W. Vaughan, R. M. A. Swalehe, N. Rao, P. Svenkerud, and S. Sood (1999). "Effects of an entertainment-education radio soap opera on family planning behavior in Tanzania." Studies in Family Planning 30(3): 193-211.

Röling, N. (1996). "Towards and interactive agricultural science." Journal of Agricultural Education and Extension 2(4): 35-48.

Röling, N., J. Ascroft, and F. Y. Chege (1976). "The diffusion of innovations and the issue of equity in rural development." Communication Research 3: 155-170.

Röling, N. G. and A. E. Wagemakers (2000). Facilitating Sustainable Agriculture: Participatory Learning and Adaptive Management in Times of Environmental Uncertainty. Cambridge, UK: Cambridge University Press.

Ryan, B. and N. C. Gross (1943). "The diffusion of hybrid seed corn in two Iowa communities." Rural Sociology 8: 15-24.

Scoones, I. and Thompson J. (eds.) (1994). Beyond Farmer First: Rural People's Knowledge, Agricultural Research and Extension Practice. London, England: Intermediate Technology Publications.

Semgalawe, Z. M. (1998). Household Adoption Behavior and Agricultural Sustainability in the Northeastern Mountains of Tanzania: The Case of Soil Conservation in the North Pare and West Usambara Mountains. Wageningen, The Netherlands: Wageningen Agricultural University. 
Sharp, L. (1952). "Steel axes for Stone-Age Australians." In E. H. Spicer (ed.), Human Problems in Technological Change, (pp. 69-91). New York, New York: Russell Sage Foundation.

Shaxson, L., and J. Bentley (1991). Economic Factors Influencing the Choice of Pest Control Technology by Small-Scale Honduran Farmers. Chatham, UK: Natural Resources Institute.

Shiva, V. (1991). "The violence of the green revolution: Ecological degradation and political conflict in Punjab." Ecologist 21(2): 57-60.

Silverman, L. J. and W. C. Bailey (1961). "Trends in the adoption of recommended farm practices." Bulletin 617. Stage College, Mississippi: Agricultural Experiment Station.
Swanson, T. M. (2002). Biotechnology, Agriculture and the Developing World: The Distributional Implications of Technological Change. Cheltenham, UK: Edward Elgar Publishing.

Wozniak, G. D. (1987). "Human capital, information, and the early adoption of new technology." The Journal of Human Resources 22(1): 101-112.

Address for correspondence: Laura German African Highlands Initiative, World Agroforestry Centre (ICRAF), P.O. Box 26416, Kampala, Uganda

Phone +256-712-220600; Fax 256+41-223242;

E-mail: L.German@cgiar.org 